\title{
Effects of Panax Ginseng Alcoholic Extract on Histomorphometric Changes of Ovaries in Offspring Rats from Diabetic Mothers
}

\author{
Afshin Zare* and Zabihollah Khaksar \\ Department of Basic sciences, School of Veterinary Medicine, Shiraz University, Shiraz, Iran. \\ http://dx.doi.org/10.13005/bbra/2027
}

(Received: 15 February 2015; accepted: 20 March 2016)

\begin{abstract}
Diabetes mellitus is one of the most common diseases of the body's endocrine system; and despite great progresses in its controlling in pregnant women the risk of birth of abnormal babies in these patients is significantly higher than healthy people. Now, the original and effective treatment of diabetes is consumption of insulin and glucose-lowering chemical medicines. But, these compounds have numerous side effects. According to this, consumption of medicinal plants in order to reduce the complications of the disease during pregnancy period is recommended. So this study is aimed to investigate possible morphological changes resulting from administration of the extraction of Panax ginseng root on ovarian tissue changes of three-month-old-rats born to diabetic mothers. A number of 32 adult female Sprague-Dawley rats approximately weighing 200$250 \mathrm{~g}$ were prepared and divided into four groups of eight each that included: healthy control group (the rats were kept without receiving any material), diabetic control group (the rats received $50 \mathrm{mg} / \mathrm{kg}$ Streptozotocin as intraperitoneally), ginseng control group (the rats received $400 \mathrm{mg} / \mathrm{kg}$ oral dose of Panax ginseng extract) and ginseng treatment group (the rats received $50 \mathrm{mg} / \mathrm{kg}$ dose of Streptozotocin as intraperitoneally and $400 \mathrm{mg} /$ kg oral dose of Panax ginseng extract). After becoming pregnant and passing from this period, a number of five three-month-old female rat infants were selected from each group. The animals were then dissected and their ovarian tissues were removed for tissue studies and H-E staining. Number of primordial follicles in diabetic control group had significant reduction compared to healthy control group. Also the number of primordial follicles in ginseng control group had significant increase compared to diabetic control group. Diameter of primordial, primary, secondary and graafian follicles and corpus luteum had significant decrease compared to the healthy control group. Also the size of primordial, primary, secondary and graafian follicles and corpus luteum had significant increase in ginseng control group compared to diabetic control group. The size of primordial follicle in ginseng treatment group had significant increase compared to diabetic control group $(\mathbf{p}<\mathbf{0 . 0 5})$. Given the above, it is found that the number and the size of ovarian follicles in three-month-old infants born to diabetic mother rats had reduced due to production of free radicals as well as induction of apoptosis; and Panax ginseng extract, due to its antioxidant compounds and also its apoptogenic properties, had improved changes of ovarian tissue in infants born to diabetic mother rats.
\end{abstract}

Keywords: Histomorphometric, Ginseng, Changes of Ovarian Tissue, Diabetic Mother Rats.

Diabetes mellitus is one of the most common diseases of the endocrine system and it occurs due to lack of cellular uptake of blood

\footnotetext{
* To whom all correspondence should be addressed. Tel :+989171065789;

E-mail : zareafshin86@gmail.com
}

glucose resulting from decreased secretion of insulin and/or resistance of cells to insulin ${ }^{1,2}$. The disease has two types including, insulin dependent (Type 1) and non-insulin dependent (Type 2) diseases. Diabetes causes numerous complications such as nephropathy, neuropathy, retinopathy and 
atherosclerosis. Neurological complications are late complications of diabetes that causes numbness in the lower limbs of the patients ${ }^{3}$.

Despite great progress in the control of diabetes complications in pregnant women, the risk of birth of abnormal babies still significantly high in those patients compared to healthy people ${ }^{4,5}$. According to available hypothesis, there is a positive relationship between poor diabetes control in early period of pregnancy and important congenital anomalies. Some of these anomalies include: hypertrophic cardiomyopathy, meningocele, anencephaly, as well as abnormalities in central nervous system (CNS), spinal cord, urinary tracts and reproductive systems ${ }^{6-9}$ (Khaksar et al. 2013 and 2014). High blood glucose levels in pregnant mother causes higher transmission of glucose to the fetus and increased secretion of insulin in its body, resulting in increased fat storage and an abnormal enlargement of the fetus body that is called Macrosomia ${ }^{10-15}$. It can be said with regard to the results obtained from these studies that diabetes control in pregnant mother is essential and necessary to prevent from occurrence of such complications.

The original and effective treatment of diabetes is consumption of insulin and glucoselowering chemical medicines. However, these compounds have numerous complications. So, it seems necessary to access to compounds that can reduce blood sugar with minimal side effects during pregnancy period and also with minimal side effects on the fetus. Due to the fact that the medicinal plants have fewer side effects than chemical medicines, researchers have been searching for herbal combinations to treat and/or prevent from the disease ${ }^{16}$. Panax ginseng, which belonging to the Araliaceae family, was used in this study. The root of this plant contains a type of steroidal glycoside called ginsenoside. Ginsenoside with the scientific name of Saponins Trip Terpenoid is also known as panaxoside in Panax ginseng $\operatorname{root}^{17}$. Numerous studies have been conducted about anti-diabetic effect of this plant [18-24]. Ginseng root has been used for centuries toward improvement in memory function, reduction of stress and improvement of impotency, weakness, and other symptoms caused by aging, as well as for increase of life time ${ }^{17}$. It was stated about the effects of ginseng on changes of ovarian tissue in mice undergoing chemotherapy that its extract respectively results in increase and reduction of the number of ovarian and atresia follicles in the group undergoing chemotherapy and as a result will reduce sexual activities (Nazari et al. 2014).

According to the above, this study is aimed to investigate the possible histomorphometric changes resulting from the administration of the extraction of Panax ginseng root on changes of ovarian tissue in three-monthold female rat infants born to diabetic mothers.

\section{METHODS}

A number of 32 adult female SpragueDawley rats approximately weighing 200-250 g were prepared and after selection of the rats as well as obtaining of required adaptation, they were kept in new conditions and in standard cages for 10 days.

The first group: the rats in this group were not diabetic during the study and did not get Panax or red ginseng extract (healthy control group).

The second group: the rats in this group became diabetic during the study. But did not get Panax or red ginseng extract (diabetic control group).

The third group: the rats in this group were not diabetic during the study, but they received 400 $\mathrm{mg} / \mathrm{kg}$ body weight oral dose of Panax ginseng extract (ginseng control group) ${ }^{18}$.

The forth group: the rats in this group became diabetic during the study and they received 50 $\mathrm{mg} / \mathrm{kg}$ dose of Streptozotocin as intraperitoneally and $400 \mathrm{mg} / \mathrm{kg}$ oral dose of Panax ginseng extract (ginseng treatment group) ${ }^{18}$.

\section{Induction of diabetes in rats}

Streptozotocin was used for induction of diabetes in this study. A dose of $50 \mathrm{mg} / \mathrm{kg}$ body weight of this medicine was injected intraperitoneally [26-28]. Blood sugar test was performed before injection and 24 hours after that time to confirm diabetes and this process was done again 10 days after injection for confidence from the establishment of the disease. Blood samples were obtained from rat tails through small incision in this organ. Diabetes level was measured through glucometer device. Blood sugar higher than 250 $\mathrm{mg} / \mathrm{dl}$ was considered as the criterion of catching diabetes ${ }^{29}$. 


\section{Extraction Method}

After preparing the raw roots of Panax ginseng from market, they steamed at 100 ÚC for two hours. The roots were then dried at 60 ÚC. The resulting product is called red ginseng [20]. The red ginseng roots became powder with an electric mill. $1000 \mathrm{gm}$ of red ginseng root powder were soaked in two liters of ethanol $90 \%$ and were kept in refrigerator for 5 days while this mixture

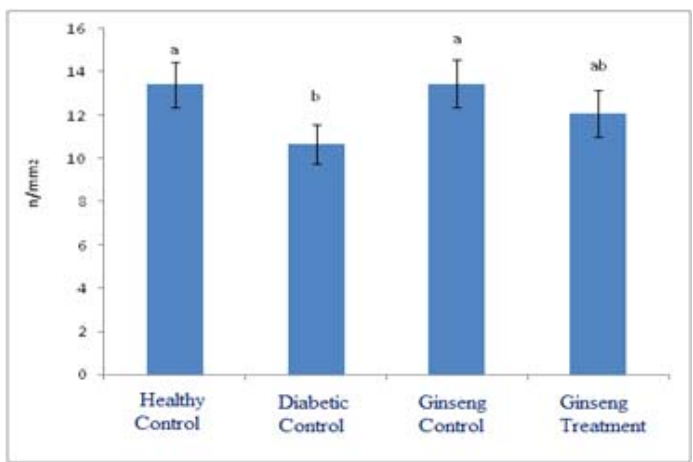

Fig. 1. The average number of ovarian primordial follicles in the studied groups

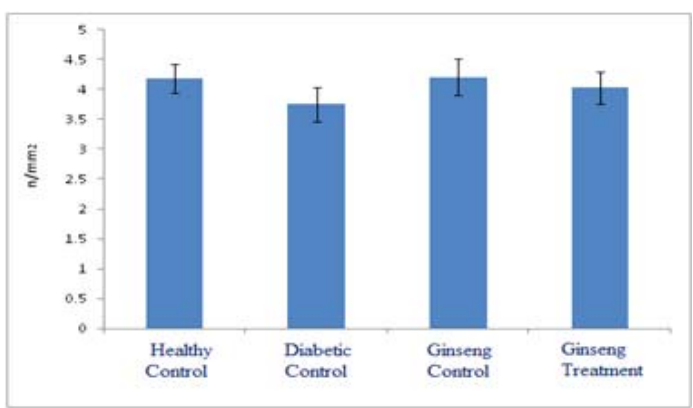

Fig. 3. The average number of ovarian secondary follicles in the studied groups

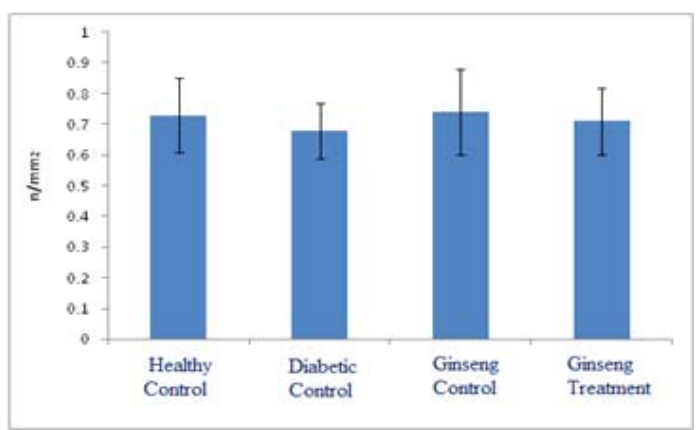

Fig. 5. The average number of ovarian corpus luteum in the studied groups was daily stirred. After five days, the resulting solution was passed through a paper filter and dried in an oven at 37 ÚC $^{18,30}$. The required amount of dried powder of red ginseng extract was daily dissolved in water and the animals were fed by it through special stomach tube.

Followed by division of the rats into four groups of 8 each, the rats in the second and the forth groups became diabetic by intraperitoneally

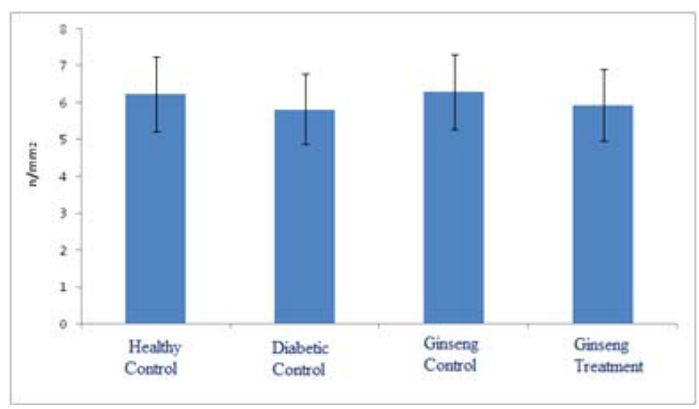

Fig. 2. The average number of ovarian primary follicles in the studied groups

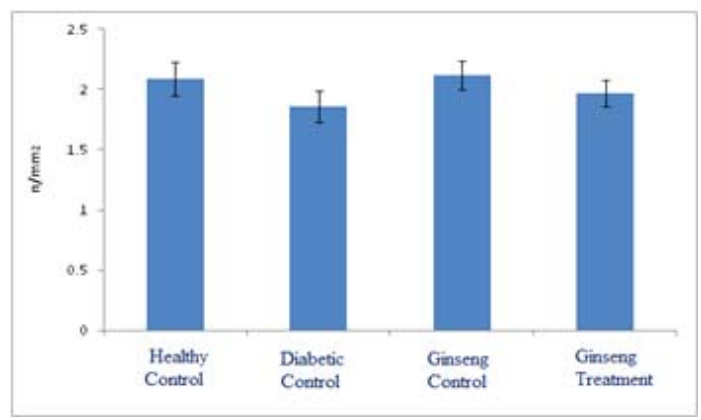

Fig. 4. The average number of ovarian graafian follicles in the studied groups

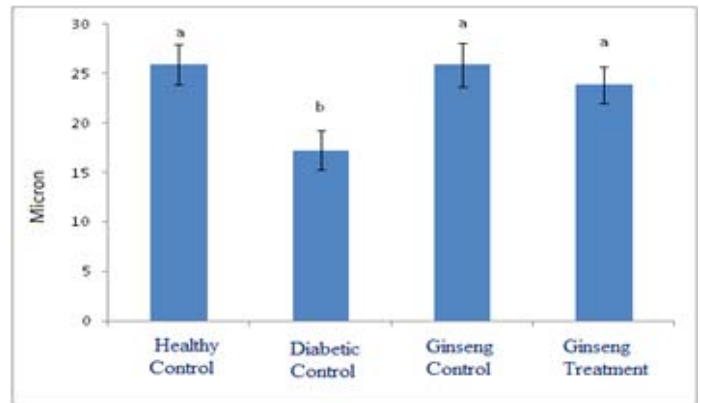

Fig. 6. The diameter of ovarian primordial follicles in the studied groups 
injection of $50 \mathrm{mg} / \mathrm{kg}$ body weight Streptozotocin ${ }^{26-}$ ${ }^{28}$. Followed by stabilization of diabetes (high glucose level and urine volume), the rats with respect to expansion of vagina were placed beside male rats for fertilization. At the end of pregnancy period, the mother rats had normal delivery. Five female rats born to these mothers were killed at the end of the third month, painlessly and humanely. Then their ovaries removed and were studied in

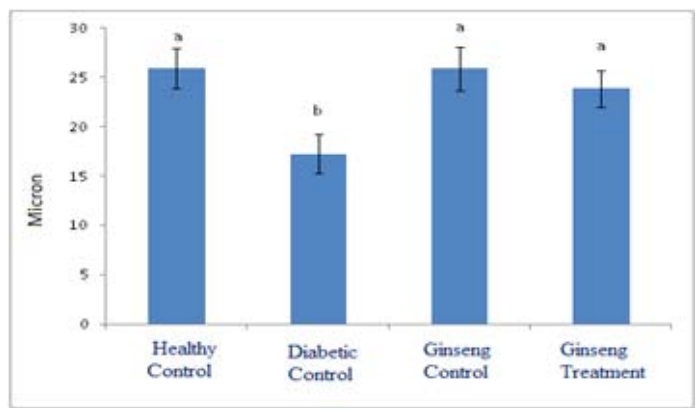

Fig. 7. The diameter of ovarian primary follicles in the studied groups

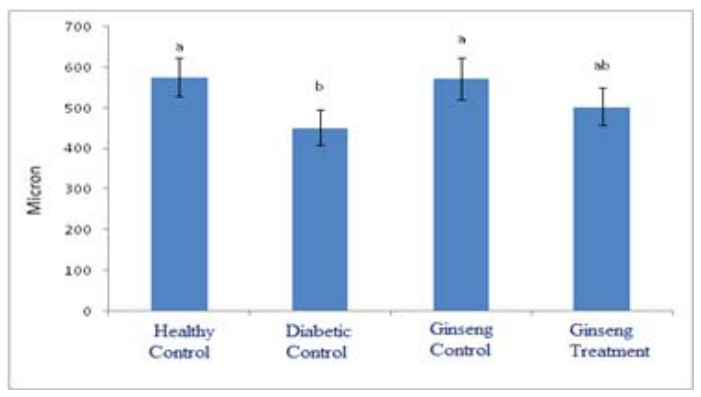

Fig. 9. The diameter of ovarian graafian follicles in the studied groups

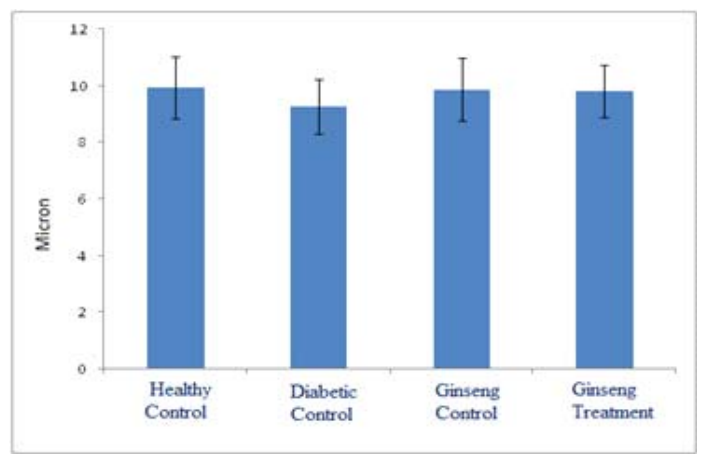

Fig. 11. The thickness of ovarian capsule in the studied groups continues. At least 5 rats (infants) in different groups were investigated for microscopic studies. Tissue sections were prepared serially from ovaries in all the studied groups for histomorphometric studies. The prepared slides were stained with Haematoxylin-Eosin stain (H\&E stain). Histomorphometric studies were done using Olympus BX51 microscope and Olysia software. The number and diameter of ovarian follicles as

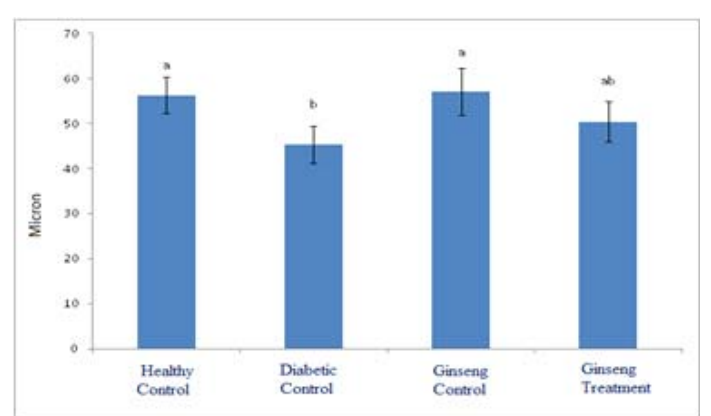

Fig. 8. The diameter of ovarian secondary follicles in the studied groups

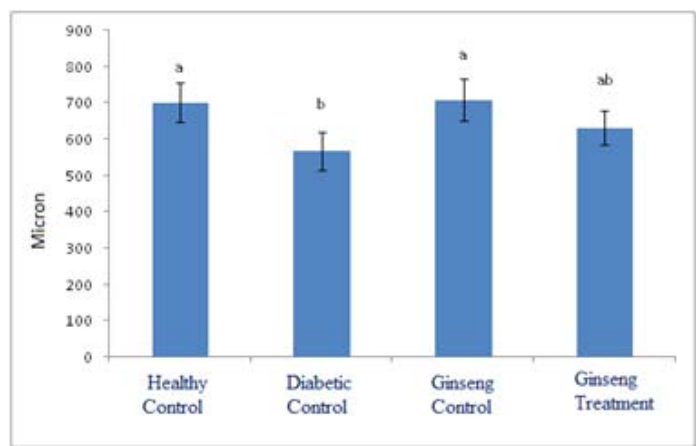

Fig. 10. The diameter of ovarian corpus luteum in the studied groups

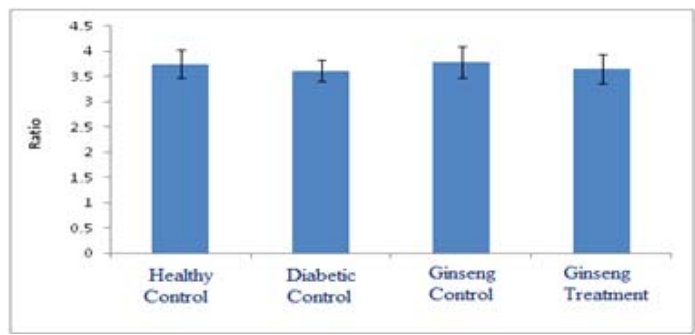

Fig. 12. The ratio of ovarian cortex to medulla in the studied groups 
well as the size of ovarian capsule and the ratio of cortex to medulla were examined. The obtained information were eventually evaluated using oneway analysis of variance (one-way ANOVA) and Duncan tests (significance level $\mathrm{P}<0.05$ ).

\section{RESULTS}

According to the figure 1, the number of primordial follicles had significant reduction in diabetic control group compared to healthy control group at $5 \%$ level. A significant increase was also observed in ginseng control group in terms of the number of primordial follicles compared to diabetic control group at 5\% level, which showed the positive effects of Panax ginseng extract on improvement of tissue complications of diabetes. According to the Figure 2 to (5) the number of primary, secondary and graafian follicles and corpus luteum reduced in the experimental groups compared to healthy control group. These changes were not statistically significant at $5 \%$ level.

According to the figure 6 to 10, the diameter of primordial, primary, secondary and graafian follicles and corpus luteum had significant reduction compared to healthy control group at $5 \%$ level. This showed a negative impact of diabetes on changes of ovarian follicle sizes. Also the sizes of primordial, primary, secondary and graafian follicles and corpus luteum in ginseng control group had significant increase compared to diabetic control group at $5 \%$ level. The size of primordial follicles in ginseng treatment group had significant increase compared to diabetic control group at $5 \%$ level, which showed the positive impacts of the extract on improvement of diabetes complications in ovaries of three-month-old female rat infants born to diabetic mothers.

According to the figures 11 and 12, the thickness of ovarian capsule as well as the ratio of cortex to medulla in the experimental groups did not have significant changes compared to healthy control group.

\section{DISCUSSION}

It was stated in researches that maternal diabetes can cause changes in histomorphometry of fetal and neonatal ovaries, so that the ovarian volume and number and diameter of the ovarian follicles will be affected and this causes irreversible damages on reproductive system of the infants born to diabetic mothers. It was also stated that diameter and weight of ovaries and thickness of ovarian capsule reduce in diabetic groups (10-15, 31-33), which is consistent with the results of this study. Garris et al. reported that diabetes causes atrophy in the ovarian follicles ${ }^{34}$. Other studies stated that increased apoptosis as well as destruction of germinal vesicles in mature phase of oocytes and ovarian is observed in maternal hyperglycemia and hyperinsulinemia models, which shows negative impacts of diabetes on development of ovarian follicles ${ }^{35}$.

Previous studies also stated that maternal diabetes causes increased apoptosis in ovarian and oocytes due to increased level of Cytochrome $\mathrm{C}$ and impact on cumulus cells [36]. It is also possible in the present study that reduced diameter and number of follicles to be due to the enhancement of apoptosis resulting from diabetes incidence, which is consistent with results of pervious researches. As the results of this study showed, the number of primordial follicles in diabetic control group had significant reduction compared to healthy control group. The diameter of primordial, primary, secondary and graafian follicles and corpus luteum in diabetic control group had significant reduction compared to healthy control group at $\mathrm{P}<0.05$ level, which indicates that diabetes has a negative impact on ovarian tissue as well as on follicles diameter.

It has been suggested in studies that diabetes leads to impaired in ovarian function including changes in follicular growth and decline or lack of ovulation ${ }^{37-39}$. Moreover, reduction of ovarian follicles, creation of atretic follicles as well as changes of ovarian volume has been reported after histopathological changes in the ovaries ${ }^{40,41}$. Examinations on impact of diabetes on ovarian tissue showed that the disease can reduce the number of oocyte microvillus and make the transparent membrane and the thinner diameter of ovarian follicles ${ }^{42}$. Studies showed that diabetes causes disruption in hypothalamic-pituitaryovarian axis. LH and FSH hormones levels will reduce and the ability of the ovaries will also reduce to synthesis sexual hormones (estrogen and progesterone), due to this disorder. It was also stated in studies that reduction of pituitary 
gonadotropins can lead to induction of apoptosis ${ }^{37}$, which is followed by reduced performance of follicles and ovarian tissue. So, the diameter and the number of ovarian follicles will also reduce. Moreover, diabetes has degenerative effect on oocyte follicles and inhibits sexual maturation of oocytes and also reduces sexual follicles due to production of free radicals ${ }^{43-45}$. It is also possible in this study that reduced diameter and number of ovarian follicles to be due to disruption of sexual hormones and also enhancement of reactive oxygen species, which is consistent with results of previous researches.

Other studies showed that due to disorder in mitochondrial performance as well as reduced energy level, diabetes causes changes in ovarian follicles, and the maturation of oocytes is also declined by $\mathrm{it}^{46}$. Due to disorder in mitochondria, diabetes produces anaerobic energy in ovarian follicles that it plays an important role in apoptosis process and creation of reactive oxygen species $^{46}$. It is likely that diabetes in this study also causes disorder in mitochondria and increases reactive oxygen species as well as apoptosis, which seeks to reduce the number and diameter of ovarian follicles and also to reduce the thickness of ovarian capsule and the ratio of ovarian cortex to medulla. This is consistent with results of previous researches.

Studies have found that diabetes leads to production of reactive forms of oxygen, reduce of antioxidant defense system and causes oxidative stress in different tissues ${ }^{47}$. The consequence of oxidative stress is damage to DNA, proteins and lipids, disorder in cellular homeostasis and accumulation of damaged molecules. So, oxidative stress is one of the mechanisms and products of diabetes, which has significant role in occurrence of tissue complications ${ }^{48}$. On the other hand, as mentioned earlier, diabetes and also its final products can also be transmitted from mother to fetus causing an adverse impact on the body organs especially the reproductive system. The results of this study also showed that maternal diabetes reduces the number and diameter of ovarian follicles, which indicates impairment in the ovaries of babies.

The results of this study showed that increased number and diameter of ovarian follicles is observed in ginseng control group compared to healthy control group. Increased number and diameter of ovarian follicles is also observed in ginseng treatment group compared to diabetic control group, which indicates the positive effects of Panax ginseng extract in reducing tissue complications in rat infants born to diabetic mothers.

Studies have indicated that the medicinal properties of ginseng plant are related to its roots. By applying techniques of extraction, constituents of ginseng roots have identified and it has become clear that ginseng roots contain triterpenesaponins, essential oils, polyacetylene, polysaccharides, peptidoglycans, nitrogenous compounds, fatty acids, carbohydrates and phenolic compounds ${ }^{49}$. The most important active ingredient of the plant is sennosides (saponins) which has triterpene structure and the pharmacological activities of ginseng plant relates to this compound ${ }^{50}$. Ginseng is considered as an adaptogenic plant ${ }^{51,52}$. Adaptogen means herbal products with antioxidant activities which are increaser of the body resistance against stressful factors, trauma, anxiety, etc. ${ }^{53}$. As becomes clear, diabetes causes oxidative stress and programmed cell death; and ginseng due to its antioxidant properties reduces and improves ovarian tissue complications in the treatment groups. Studies have indicated that ginseng has positive supporting and curative effects against testicular disorders caused by some materials such as 8, 7, 3, 2-tetra-chloro dioxin ${ }^{54,55}$. By its antioxidant activity, ginseng can remove superoxides and by inhibition of activities of hydroxyl radicals and anions, it can prevent lipids peroxidation in cellular membrane ${ }^{55}$. Studies have found that oxidative stress in diabetic conditions has been observed in some polyphenols in animals ${ }^{56}$, which is consistent with the results of this study. This reflects the positive properties of ginseng extract on improvement of the number and diameter of ovarian follicles in treatment group compared to diabetic control group.

As mentioned above, diabetes reduces secretion of these hormones ( $\mathrm{LH}$ and FSH hormones) and thus reduces maturity of ovarian follicles. So, any factor that can increase these hormones, have treatment effect on improvement of changes of ovarian tissues caused by diabetes. Studies conducted in the past have found that ginseng has impact on the anterior pituitary and 
secretion of nitric oxide. This impact is applied due to the presence of ginsenosides (saponins). It seems that nitric oxide also impacts on ovarian arteries. Thus, LH and FSH levels will also increase by enhancement of nitric oxide, and vice versa [58]. So this probability also exists in this study that ginseng increases secretion of nitric oxide and this material can release LH and FSH by impact on pituitary gland and thus the number and diameter of follicles will increase.

\section{CONCLUSIONS}

Given to the above, this study indicates that due to production of free radicals and also induction of apoptosis, the number and size of ovarian follicles have reduced in three-month-old female rat infants born to diabetic mothers. The extract of Panax ginseng root due to its antioxidant compounds and its adaptogenic properties improves ovarian tissue in three-month-old female rat infants born to diabetic mothers. So, the extract is recommended to use, since it will be able to reduce the complications of diabetes.

\section{REFERENCES}

1. Li, W.L., Zheng, H.C., Bukuru, J. and De Kimpe, N., 2004. Natural medicines used in the traditional.

2. Nakamura, U., Iwase, M., Uchizono, Y., Sonoki, K., Sasaki, N., Imoto, H., Goto, D. and Iida, M., 2006. Rapid intracellular acidification and cell death by $\mathrm{H} 2 \mathrm{O} 2$ and alloxan in pancreatic $\beta$ cells. Free Radical Biology \& Medicine, 40: 20472055.

3. Jones,C.W. 2001. Gestational diabetes and its impact on the neonate. Neonatal Network. 20(6):17-23.

4. Lea RG.,Richard G.,Mccrecken JE., 1996. Distributed development of the preimplantationemboryos in the insulindependent diabetic BB/E rats. Diabetes; 45(11):1463-1470

5. Mills JL.,Knopp RH., Simpson JL., Jovanovicpeterson L., .1998. Lack of relation of increased malformation rats in infants of diabetic mother to glycemic control during organogenesis. New.EngJMed; 318: 671-676.

6. Farrell T. et al. 2002. Congenital anomalies in the offspring of women with Type 1, Type 2 and gestational diabetes. Diabetes UK Diabetic Medicine, 19; 322-326.
7. Martinez-Frais. et al (1998).Analysis of Outcomes of Pregnancy in Gestational Diabetic Mothers. American Journal of Medical Genetics 78:140-145.

8. Cloherty. J and stark. Manual of neonatal carc. ( $4^{\text {th }}$ edition) hittle Brown and co.: Boston massachusetts 1998.

9. AbergA.andet al. 2002. Congenital malformation among infants whose mothers had gestational diabetes or preexisting diabetes. Early Human Development 6(1): 85-95.

10. Khaksar Z, Jelodar G, Hematian H, Poor ahmadi M (2014) Ultrastructural changes in rat ovarian cells of fetuses and neonates from diabetic mothers. Comparative clinical pathology 23: 1167-1171

11. Khaksar Z, Jelodar G, Hematian H, Poor ahmadi M (2013): Ovarian Histomorphometry at Puberty in Rat Offspring from Diabetic Mothers World Journal of Zoology 8 :24-29

12. Khaksar Z, Jelodar G, Hematian H, Poor Ahmadi M (2013) : The Histomorphometric Effects of Maternal Diabetes on Rat Offspring's Ovaries at the Puberty Journal of Infertility and Reproductive Biology 1:48-53

13. Khaksar Z, Jelodar G, Hematian H, Poor Ahmadi M (2013): Alterations in gonadal and testicular cells of male fetuses and neonates of diabetic rats Comparative clinical pathology 22:11111115

14. Khaksar Z, Jelodar G, Hematian H, Poor Ahmadi M (2013) : Alterations of the ovarian histomorphometry at pre-puberty in rat offspring from diabetic mothers Reproductive medicine and biology 12:173-178

15. Khaksar Z, Jelodar G, Hematian H, Poor Ahmadi M (2013): Ovarian histomorphometric changes in adult offspring of diabetic rat mothers Comparative Clinical Pathology 22:239-244.

16. Isah, A.B., Ibrahim, Y.K.E., Abdulrahman, E.M. and Ibrahim, M.A., 2007. The hypoglycaemic activity of the aqueous extract of Stachytarphetaangustifolia(Verbanaceae) in normoglycaemic and alloxaninduced diabetic rats. Pakistan Journal of Biological Science, 10(1): 137-141.

17. Sun L Q. 2004. Information on research and application of Ginseng, the king of traditional and herbal medicines. Asian Journal of Drug Metabolism and Pharmacokinetics. 4(4):261284.

18. Raya A O, Alfky N A and Elgazar A F. 2013. Anti-obesity and antidiabetic Activities of red ginseng plant extract in obese diabetic male rats. Global journal of pharmacology. 7(4): 390-397.

19. Hong B N. Ji M G. Kang T H. 2013. The efficacy 
of red Ginseng in type 1 and type 2 diabetes in animals. Evidence - based complementary and alternative medicine. 593181, 7 pages.

20. Lee M R. Yun B S. 2011. Comparetive study of Korean white, red and black Ginseng extract on cholinestrase inhibitory activity and cholinergic function. Journal of Ginseng research. 35(4): 421-428.

21. Sawriss F. A. R. 2011. Effect of Ginseng extracts supplementation on renal function in Diabetic Rats. Journal of agricultural science. 3(2): 1723.

22. Shishtar E and Jovanovski E. 2014. Effect of Korean White Ginseng on vascular and glycemic health. Clinical nutrition research. 3: 89-97.

23. Park S Y, Seo J H and Kim J K. 2014. Effect of Korean Red Ginseng on hearing and blood glucose levels in steriod therapy for sudden sensorineural hearing loss. Clinical and exprimental otorhinolaryngology. 7(3): 170-174.

24. Arafa R M. 2013. Influence of ginseng, curcumin and their combination on rats suffering from diabetes and acute liver diseases. World applied science journal. 26(10): 1391-1399.

25. Nazari F, Johari H A, Hemayat-khahJahromi et al. (2014). The impact of aqueous and alcoholic extract of ginseng on the removal of toxicity caused by cyclophosphamide in ovarian tissue of adult female rats. Pars Journal of Medical Sciences. 12(3):23-30

26. Asadi F, et al. (1999). Investigation on treatment effects of Cuminumodorumsalisb on experimental diabetes in male rats. Papers Abstracts of Iran's Fourteenth Congress of Physiology and Pharmacology. pp 347

27. Roghani M et al. (1999). Analgesic effect of aqueous extract of fenugreek leaves on male rats with Streptozotocin-induced diabetes mellitus using Farmalyn test during both acute and chronic phases. pp 342

28. Nickbakht M, Ghaytasi, Izadpanah. (2006). Hypoglycemic effect of aqueous and alcoholic extract of Colocynth on normoglycemic male rats with Streptozotocin-induced diabetes. Scientific Journal of Armaghan-e Danesh. 6371:42

29. Jafari M, Khaksar Z. (2012). The effect of Aloe vera extract on fetal testis tissue of diabetic rats. Scientific Journal of Yasouj University of Medical Science. 149-155:(2)17

30. DivebandKh, KomeiliGh, Saeidi Nick F. (2010). The effect of aqueous extract of walnut leaves on serum glucose and lipid levels of diabetic rats. Scientific Journal of Birjand University of Medical Science. 11-18:(1)17

31. Jelodar G, Khaksar Z, Poor ahmadi M (2010)
Endocrine profile and testicular histomorphometry in neonatal rats of diabetic mothers veterinarskiarhiv 3:421-430

32. Jelodar G, Khaksar Z, Poor ahmadi M (2010) Endocrine profile and testicular histomorphometry at puberty in rat offspring from diabetic mothers Comp ClinPathol 19:135139

33. Jelodar G, Khaksar Z, Poor ahmadi M (2009) Endocrine profile and testicular histomorphometry in adult rat offspring of diabetic mothers The journal of physiological sciences 59: 377-382

34. Garris DR, Williams SK, West L (1985) Morphometric evaluation of diabetes-associated ovarian atrophy in the C57BL/KsJ mouse: relationship to age and ovarian function. Anat $\operatorname{Rec} 211(4): 434-443$.

35. Chang SA, Dale NA, Oley HK (2005) Maternal diabetes adversely affects preovulatory oocyte maturation, development, and granulosa cell apoptosis. Endocrinology 146(5):2445 2453.

36. Lin S, Lin K, Li W, Zhou X, Huang T (2010) Maternal diabetes increases apoptosis in mice oocytes, not 2-cell embryos. Endocrine 37(3):460-466.

37. Ballester J, Munoz MC, Dominguez J, Palomo MJ, Rivera M, Rigau T, et al. Tungstate administration improves the sexual and reproductive function in female rats with streptozotocin induced diabetes. Hum Reprod2007; 22(8): 2128-35.

38. Colton SA, Pieper GM, Downs SM. Altered meiotic regulation in oocytes from diabetic mice. BiolReprod2002; 67(1): 220-31.

39. McLean Mp, warden kJ, Sandhoff TW, Lrby RB, Hales DB. Altered ovarian sterol carrier protein expression in the pregnant streptozotocin-treated diabetic rat. BiolReprod1996; 55(1): 38-46.

40. Codner E, Soto N, Lopez P, Trejo L, Avila A, Eyzaguirre F.C, et al. Diagnostic criteria for polycystic ovary syndrome and ovarian morphology in women with type 1 diabetes mellitus. JClinEndocrinolMetab2006; 91(6): 2250-6.

41. Albrecht $\mathrm{G}$, Hahn von Dorsche H. Quantitative histologic studies of the gonads of sand rats (Psammomysobesus) during the development of diabetes mellitus. AnatAnz1991; 173(2): 1015 [Article in German].

42. Pournaghi P, Sadrkhanlu R A, HasanzadehSh et al. (2011) Microscopic study of oocytes and ovarian follicles transparent membrane of rats following induction of experimental diabetes and treatment with metformin. Journal of Tehran 
University of Medical Science. 69(6):366-373

43. Sinclair AJ, Lunec J. Free radicals, oxidative stress and diabetes mellitus. In: Blake D, Winyard PG, editors. Immunopharmacology of Free Radical Species. London: Academic Press; 1995. p. 183-98.

44. Rains JL, Jain SK. Oxidative stress, insulin signaling, and diabetes. Free RadicBiol Med 2011;50(5):567-75.

45. Roberts CK, Sindhu KK. Oxidative stress and metabolic syndrome. Life Sci2009;84(2122):705-12.

46. Ghadially FN. Ultrastructural Pathology of the Cell and Matrix. $4^{\text {th }}$ ed. Boston: ButterworthHeinemann; 1997l1. p. 246-9.

47. Brownlee, M. (2001). Biochemistry and molecular cell biology of diabetic complications. Nature, 414; 813-820.

48. Jakus, V. (2000). The role of free radicals, oxidative stress and antioxidant systems in diabetic vascular disease. Bratisl. Lek. Listy, 101; 541-551.

49. Kumar A. 1993. Chemopreventive action of ginseng on DMBA induced skin papillomagenesis in the skin of Swiss albino mice. Proceedings of the 6th International Ginseng Symposium, 6-9; Seoul Olympic Parktel. Seoul, Korea: Korea Ginseng \& Tobacco Research Institute, P: 66-8.

50. Cheng LQ, Kim MK, Lee JW, Lee YJ, Yang DC.
2006. Conversion of major ginsenoside Rb1 to ginsenoside F2 by Caulobacterleidyia. BiotechnolLett, 28: 1121-1127.

51. Helms S. 2004. Cancer prevention and therapeutics: Panax ginseng. Altern Med Rev, 9(3):259-74.

52. Kitts D, Hu C. 2000. Efficacy and safety of ginseng. Public Health Nutr, 3(4A):473-85.

53. Chang YS, Seo EK, Gyllenhaal C, Block KI. 2003. Panax ginseng: a role in cancer therapy. Integr CancerTher, 2(1):13-33.

54. Kang J, Lee Y, No K, Jung E, Sung J, Kim Y, et al. 2002. Ginseng intestinal metabolite-I (GIMI) reduces doxorubicin toxicity in the mouse testis. Reprod Toxicol, 16(3):291-8.

55. Attele AS, Wu JA, Yuan CS. 1999. Ginseng pharmacology: multiple constituents and multiple actions. BiochemPharmacol, 58(11):1685-93.

56. Sanders, R. A., Rauscher, F. M., Watkins, J. B. (2001). III: effects of quercetin on antioxidant defense in streptozotocin-induced diabetic rats. J. Biochem. Mol. Toxicol, 15; 143-149

57. Murphy LL, Lee TJ. 2002. Ginseng, sex behavior, and nitric oxide. Ann N Y AcadSci, 962: 273277.

58. Cussons AJ, Stuckey BGA, Watts GF. 2006. Cardiovascular disease in the polycystic ovary syndrome: New insights and perspectives. Atherosclerosis, 185: 227-39. 